\title{
Inclusion of Students with Autism Spectrum Disorders in Italian Schools: From Theory to Practice
}

\author{
Marzia Mazzer \\ Department of Movement, Human and Health Sciences, University of Rome "Foro Italico", Rome, Italy \\ Email: marzia.mazzer@uniroma4.it
}

Received 27 August 2015; accepted 15 September 2015; published 18 September 2015

\begin{abstract}
The purpose of this paper is to provide a general overview about the issue of inclusion of students with Autism Spectrum Disorders in Italian Schools. Firstly, we will present an overall picture of the inclusion processes of students with disabilities in the Italian school system. Secondly, we will focus on teaching-learning strategies designed to meet the educational needs of students with ASD and to move towards an "inclusive classroom" in which all students, with their different abilities, are welcomed in the learning community. Finally, in order to put theory into practice, we will discuss a "case study" of a 6-year-old pupil with ASD in an Italian primary school, identifying specific barriers and facilitators to accessibility and inclusion.
\end{abstract}

\section{Keywords}

Autism Spectrum Disorders, Inclusive School, Barriers and Facilitators, Teaching-Learning Strategies, Good Practices

\section{Introduction}

Italy had adopted an inclusive scholastic model for more than forty years. The policy of "integration" has been implemented since the 1970s (Law n 118/1971; Law n 517/1977) in order to guarantee everybody's right to attend ordinary schools and quality education. Since then, the Italian school system has undergone through several transition and changes for the purpose of providing more and more concrete answers to everyone's educational needs [1].

Since the beginning, it has been clear that the success of every integration/inclusion process was grounded in the collaboration and active cooperation of different agents: school staff (dean, teachers, assistants, classmates, school administrators, paraprofessionals, lunch and recess aides, etc.), family and socio-sanitary services. Building this network of alliances also represents the key to guarantee the necessary continuity between school and work in the perspective of the student's "life project" [2].

A very important node of this network is represented by the figure of the specialized teacher that was first introduced by Law $n^{\circ} 517 / 1977$. A specialized teacher is assigned to every classroom in which there is a student 
with disability in order to co-work with the curricular teachers and to facilitate the process of inclusion.

Specialized teacher together with general teachers, parents and socio-sanitary services has to draw up the Individual Educational Planning (IEP) of the student with disability (Law n ${ }^{\circ}$ 104/1992). IEP described goals to be reached and strategies and evaluation criteria to be used in a certain period of time. IEP is conceived to implement the right of every student to education and to promote autonomy, social skills, learning and inclusion.

Given this general framework, we are now going to analyze in more detail some educative strategies that can be useful to make school an inclusive context for all.

\section{Educative Strategies to Foster Inclusion at School}

As a growing number of evidences suggests, the teamwork between specialized and general teachers represents the first step to improve the learning processes and to facilitate the active participation of all the students and, in particular, of students with disabilities [3] [4].

Working in team means:

1) Sharing knowledge: firstly, all the members of the teaching staff should acquire a general knowledge about special education in order to support the learning process of all the students. However, it is important to note that every student is unique. That means each one has different characteristics as well as different styles of learning. Therefore, a general knowledge is not enough. Teachers should learn how to deal with their specific student and this requires a specific knowledge of his way of functioning and of his specific story. In this phase, parents can be very helpful because they can provide a large amount of information about their son/daughter's strengths and weaknesses, tastes, preferences, habits, fears and past experiences [5].

2) Co-planning the didactic: general and specialized teachers need to co-plan and prepare lessons, activities and projects that incorporate all learning modalities. Italian legislation requires part of the teacher's working time to be used in co-planning. This phase is crucial to reflect about teaching methods and strategies that can fit every single student.

3) Co-teaching in classroom: both teachers share responsibilities for delivering instruction, assessment and class management and for providing supports and accommodations to meet the needs of all students [6].

Classmates can represent the most precious resource for inclusion but, in order to take full advantage of it, teachers have to foster empathy and prosocial behaviors. This may require a radical rearrangement of the traditional didactic lecture in favor of more participative teaching-learning strategies that can enhance the sense of group belongingness and lower the level of competitiveness. Here are some examples of these strategies:

1) Peer to peer tutoring: it is a method of instruction that involves students teaching other students. This strategy is mutually beneficial: tutors may increase their own understanding of the subject matter while tutees may feel more at ease in learning with a peer. Particularly, research has shown that this strategy can reinforce students' self-esteem, stimulate their interest in challenging tasks, enhance scholastic achievements and foster prosocial behavior [7] [8].

2) Metacognitive strategies: they refer to methods used to help students understand the way they learn or to "think" about their "thinking". As students become aware of how they learn, they will use these processes to efficiently acquire new information. The main metacognitive strategies that can be implemented in the classroom are: selection of the most relevant information, organization of information (e.g. by means of conceptual maps), elaboration of contents (connecting new with past knowledge) and repetition of the information (verbally, visually etc.) to stimulate memory processes [9] [10].

3) Cooperative learning: it is a teaching method which involves that students of mixed levels of ability are arranged into groups and rewarded according to the group's success. Each student is assigned a specific role and a clear task to carry out. This strategy helps to create a positive interdependence: each member perceives that working together is individually and collectively beneficial, and success depends on the participation of all the members. Through cooperative learning, students not only learn the subject matter but they also acquire the capacity to work in team, improving their sense of self-effectiveness and their interpersonal skills (e.g. communication, conflict management, leadership and collaboration) [3] [11].

\section{Students with Autism Spectrum Disorders at School}

The strategies referred to above may be supportive of all the students and, particularly, of students with Special 
Educational Needs. However, the process of inclusion of students with ASD may benefit of some additional specific adjustments.

Autism Spectrum Disorders are characterized by a highly resistant to change and a need for "sameness" [12]. Consequently, new and unfamiliar situations, unforeseen events and sudden alterations of the environment may cause anxiety and trigger challenging behaviors. In order to avoid stressful situations, it is necessary to prepare the student for changes by means of a well structured environment in terms of time and space:

1) Time structuring: using timetables/schedules to help the student to predict what is going to happen next and to inform him of any changes ahead of time.

2) Space structuring: linking particular activities to particular spaces, providing clues about what is happening in a certain space (e.g. with simple drawings or pictures), making pathways clear (e.g. signaling how to go from classroom to gym by arrows or by sticky footsteps on the floor).

Students with ASD can also present a preoccupation with narrow area of interest, an inflexible adherence to rituals, and a frequent presence of stereotyped and repetitive motor movements like rocking or hand flapping [12]. Even if these behaviors appear strange and bizarre, they may have specific functions since they can be deeply calming, they can help concentration or block out a distracting stimulus [13]. Considering these behaviors just as symptoms of a disorder and trying to extinguish them may cause suffering and anxiety. On the contrary, it is necessary to allow structured time for rituals, routines to be carried out, or special interests to be discussed and possibly shared with the classmates. Moreover, it is important to inform the student when this time will be (e.g. with an iconic symbol on the timetable).

Another relevant aspect of ASD concerns the hyper- or hypo-reactivity to sensory inputs as light levels, patterns, sounds, smells, colours, textures and tastes [12]. In her autobiography, for instance, Gillingham says: "Every time I am touched it hurts; it feels like fire running through my body" [14]. Since the specific way of perceiving the stimuli can deeply affect one student's life, it has to be taken into serious consideration both by teachers and classmates.

Finally, the most challenging trait of ASD relates to deficits in social communication and social interaction that range from failure of normal back and forth conversation to reduced sharing of emotions/affects to difficulties in engaging in social and collective activities [12]. In some cases, the total absence of verbal language makes social relationships even more difficult. Consequently, peers may feel confused, scared, disoriented, unable to connect with their companion [15]. Teachers can prevent these feelings promoting the value, the benefits and the knowledge of diversity in classroom. All the students need to be aware of their companion's specific way of functioning in order to comprehend his strengthens, support his capacities and reduce his weaknesses [16]. Peers could transform themselves in "facilitators" if they know that deficits are not intrinsic to their classmate but result from his characteristics and those of the context [17] of which they are a constituent part. They need to become conscious that they can positively affect their classmate's participation to the scholastic activities.

In order to raise classmates' awareness, teachers can use cartoons, movies, fictions, articles or autobiographies written by people with ASD (depending on the students' age) [18]. If possible, they can also ask the student's parents or the same student with ASD to talk about himself. Particularly, engaging with first person narratives is crucial to build an understanding of the everyday lived experiences of people with ASD that are often a long way from official definitions [19]-[21].

Discussions and debates should follow the above activities in order to hear everyone's opinion (even by means of focus groups, brainstorming etc). Fostering awareness and dialogue as an integrant part of the didactic program can help to eradicate such prejudices and stereotypes that may strongly influence the representation that students have of disability in general and Autism Spectrum Disorders in particular.

Finally, having diversity in classroom may benefit everyone. Evidences show that classmates of peers with disabilities feel emotionally and cognitively more mature than other students. Moreover, strategies such as tutoring and cooperative learning can improve students' self-esteem, social skills and friendships [22] [23]. Consequently, since inclusion represents a huge resource for all, it has to be consciously managed and it has not to be "wasted".

\section{From Theory to Practice: An Italian "Case Study"}

We are now going to discuss briefly an Italian case study in order to give some concrete examples of the con- 
cepts expressed above. The study was conducted in a first degree classroom of a primary school in a rural area of Tuscany (Italy) attended by sixteen students of which one with ASD.

The tools used for this study comprise semi-structured interviews with teachers and classmates and a period of direct observation in classroom. The data has been collected using a narrative methodology that we consider the most apt to describe the complexity that pertains to educational processes. Through narration, in fact, it is possible to deeply analyze experiences that are, by their nature, nuanced and hardly categorizable [24] [25]. This method of inquiry is grounded in the postmodern assumption that it does not exist a unique reality and, consequently, it is not possible to give a single interpretation of it. This assumption is based on three main principles: pluralism, relativism and subjectivity [26]. Moving from this idea, we intended to describe, interpret and understand the aforementioned experience from the reseacher-observer's point of view. The focus of this study, in particular, was on the contextual variables that we considers in terms of barriers and facilitators for implementing the process of inclusion of the pupil with ASD.

The pupil, L., is 6 years old and he has been diagnosed with ASD associated with sever cognitive impairment. His Individual Educational Planning is mainly focused on the development of capacities such as sharing attention, focusing attention on didactic activities, improving social and communication skills (his use of verbal language is pretty limited).

Data gathered through interviews and direct observation showed that some of the facilitating factors of L.'s inclusion at school have been:

1) Introduction of a daily timetable and of sequences of images that visually describe step by step every single activity (e.g.: going to toilet, having a snack, going to gym, etc.). Before the introduction of the timetable, $\mathrm{L}$. struggled to sit at his desk for the whole hour of class and exhibited frequent opposition behaviors. Timetable gave him the idea of the flow of time. Thanks to this visual representation, he understood that every activity has a start/ an end and that an appealing activity would follow a more demanding one. Moreover, by means of the sequences of images, he also became more autonomous because he could easily know what to do in order to reach a specific goal and what others expect from him.

2) Introduction of peer tutoring. Every day a different classmate is in charge of helping L. with his daily routines: entrance at school, constructing the timetable, placing the materials on the desk, etc. Before the introduction of peer tutoring, classmates felt uncertain about how to deal with L. Having a specific role to fulfill, instead, made feel them more confident. Moreover, aid relationships may lead to establish playful and social relationships. To confirm this, L. now shows more and more interest in approaching his peers. During the recess, for example, he used to run alone in the school hallway while now running has turned into a social activity. He only runs if his peers chase after him.

3) Exploitation of his specific interests to encourage learning. At the first moment, teachers were particularly worried about L.'s narrow interest for activities such as playing with sand or sorting objects by shape and colors. However, at the second moment, they learnt how to take advantage of it. They realized, for instance, that sand could be used to write letters or to draw, sorting objects could be helpful in order to learn how to categorize or how to count and so on. Also classmates have been involved in this activities, introducing little changes to well established routines.

On the other hand, we have noticed that there are a number of factors that negatively affect the process of inclusion. Here are some examples:

1) Prevalence of frontal lectures: general teachers (e.g. Italian, Science and Math) tend to prefer a traditional kind of didactic because they consider it more "functional". However, if the "one-to-many lesson" is useful to deliver a large amount of information to many students in a short time, it also presents some negative sides. Students can easily lose their attention (listening may be hard, especially for children); listening gives only access to a theoretical kind of learning that may be less stable during the time; students with special educational needs may be strongly disadvantaged [27]. Despite the potential benefits for L. and for all his classmates, working in small groups is still limited to specific subjects such as music or physical activity. An innovative didactic approach and a constructive collaboration between specialized and general teachers could be beneficial for everybody.

2) Encouraging the communication: as referred above, L's use of verbal language is pretty limited and he communicates mainly by gestures. This is clearly a barrier to social relationships. It would be useful to introduce a mutually shared visual communication system, for example, in order to provide L. with a mean to 
express himself and to be in touch with his teachers/peers. The same system could be used by the family or by the socio-sanitary assistants. Building this communication channel and learning how to use it could represent the goal of a collective and trans-disciplinary project.

The data gathered from this case study highlights the importance of working on the scholastic context at different levels (from physical environment, to classmates, to didactic, etc.) in order to meet the specific needs of students with ASD.

More generally, we can affirm that inclusion constitutes a never ending process that could be enhanced by an attentive observational skill, a constant research of innovative practice and a shared intention to experiment and to change. Furthermore, since inclusion and quality education are deeply entrenched [28], implementing such a process may be beneficial for the students, the teachers and the entire school system.

\section{References}

[1] Canevaro, A. and de Anna, L. (2010) The Historical Evolution of School Integration in Italy: Some Witnesses and Considerations. ALTER, European Journal of Disability Research, 4, 203-216. http://dx.doi.org/10.1016/j.alter.2010.03.006

[2] de Anna, L. (2014) Pedagogia speciale. Integrazione e inclusione. Carocci, Roma.

[3] Andrich, S. and Miato, L. (2003) La didattica inclusiva. Organizzare l'apprendimento cooperativo. Erickson, Trento.

[4] Cottini, L. (2011) L'autismo a scuola. Quattro parole chiave per l'integrazione, Carocci, Roma.

[5] Pavone, M., Ed., (2009) Famiglia e progetto di vita. Crescere un figlio disabile dalla nascita alla vita adulta. Erickson, Trento.

[6] Cook, L. (2004) Co-Teaching: Principle, Practice, and Pragmatics. Northridge, California.

[7] Cottini, L. (2004) Didattica speciale e integrazione scolastica. Carocci, Roma.

[8] Damon, W. (1984) Peer Education: The Untapped Potential. Journal of Applied Developmental Psychology, 5, 331343. http://dx.doi.org/10.1016/0193-3973(84)90006-6

[9] Cornoldi, C. (1995) Metacognizione e apprendimento. Il Mulino, Bologna.

[10] Friso, G., Palladino, P. and Cornoldi, C. (2006) Avviamento alla metacognizione. Mondadori, Milano.

[11] Johnson, D.W. and Johnson, R. (1999) Learning Together and Alone: Cooperative, Competitive, and Individualistic Learning. 5th Edition, Allyn \& Bacon, Boston.

[12] American Psychiatric Association (2013) Diagnostic and Statistical Manual of Mental Disorders. 5th Edition, American Psychiatric Association, Washington DC.

[13] Williams, D. (1992) Nobody Nowhere: The Extraordinary Autobiography of an Autistic. Times Book, New York.

[14] Gillingham, G. (1995) Autism: Handle with Care! Understanding and Managing Behavior of Children and Adults with Autism. Future Education Inc., Arlington.

[15] Swaim, K.F. and Morgan S.B. (2001) Children’s Attitudes and Behavioral Intentions Toward a Peer with Autistic Behaviors: Does a Brief Educational Intervention Have an Effect? Journal of Autism and Developmental Disorders, 31, 195-205. http://dx.doi.org/10.1023/A:1010703316365

[16] Cottini, L. (2013). Che cos'è l'autismo infantile. Carocci, Roma.

[17] World Health Organization (2001) International Classification of Functioning, Disability and Health: ICF. World Health Organization, Geneva.

[18] Waltz, M. (2005) Reading Case Studies of People with Autistic Spectrum Disorders: A Cultural Studies Approach to Issues of Disability Representations. Disability \& Society, 20, 421-435. http://dx.doi.org/10.1080/09687590500086575

[19] Milton, D.E.M. and Bracher, M. (2013) Autistics Speak but They Are Heard? Journal of the BSA MedSoc Group, 7, 61-69.

[20] O’Neil, S. (2008) The Meaning of Autism; Beyond Disorder. Disability \& Society, 23, 787-799. http://dx.doi.org/10.1080/09687590802469289

[21] Zappaterra, T. (2009) L'occhio interno della disabilità. Handicap e valore formativo dell'autobiografia. In: Mannucci A. and Collacchioni, L., Eds., L'avventura formativa tra corporeità ed emozioni, Edizioni ETS, Pisa, 199-218.

[22] Peck, C.A., Donaldson, J. and Pezzoli, M. (1990) Some Benefits Non-Handicapped Adolescents Perceive for Themselves from Their Social Relationships with Peers Who Have Severe Disabilities. Journal of the Association for Persons with severe Handicaps, 15, 241-249.

[23] Grenot-Scheyer, M., Staub, D., Peck, C.A. and Schwartz, I.S. (1998) Reciprocity and Friendships: Listening to the 
Voices of Children and Youth with and without Disabilities. In: Meyer, L.H., Park, H.S., Grenot-Scheyer, M., Schwartz, I.S. and Harry, B., Eds., Making Friends: The Influences of Culture and Development, Paul H. Brookes, Baltimore, 149- 167.

[24] Smorti, A. (1994) Il pensiero narrativo. Costruzione di storie e sviluppo della conoscenza sociale. Giunti, Firenze.

[25] Sorzio, P. (2002) La ricerca qualitativa in educazione. Problemi e metodi. Carocci, Roma.

[26] Santoianni, F. and Striano, M. (2005) Strutture della conoscenza. Linguaggi del pensiero. Pisanti, Napoli.

[27] Comoglio, M. (1998) Educare insegnando. Apprendere e applicare il cooperative learning. LAS, Roma.

[28] Booth, T. and Ainscow, M. (2011) Index for Inclusion: Developing Learning and Participation in Schools. Centre for Studies on Inclusive Education, Bristol. 